\title{
EFEITO DA FORMA FÍSICA E DA RESTRIÇÃO ALIMENTAR SOBRE O DESEMPENHO DE POEDEIRAS LEVES
}

\author{
Isabel Cristina Mello da Silva, ${ }^{1}$ Andréa Machado Leal Ribeiro, ${ }^{2}$ \\ Alexandre de Mello Kessler ${ }^{3}$ e Ronald Alejandro Rocha Claros ${ }^{4}$ \\ 1. Doutora em Zootecnia, Produção Animal, UFRGS \\ 2. Professora adjunta UFRGS. E-mail: aribeiro@ufrgs.br \\ 3. Professor associado, UFRGS \\ 4. Departamento de Zootecnia, UFRGS.
}

\section{RESUMO}

O experimento objetivou testar os efeitos da forma física da ração (farelada vs. peletizada) e da restrição alimentar (à vontade vs. $10 \%$ de restrição) em 160 poedeiras leves H \& N. Foram aplicados quatro tratamentos, com vinte repetições de duas aves cada, em um delineamento completamente casualizado, em arranjo fatorial 2 x 2, de 26 a 44 semanas de idade das aves. Avaliaram-se consumo de ração (CR), ganhos de peso (GP), conversão alimentar (CA), produção de ovos (PO), peso médio de ovos (PMO) e gravidade específica (GE). A ração farelada proporcionou maior
CR no período total $(\mathrm{P}<0,001)$ e a ração peletizada propiciou maior CR somente a partir das 42 semanas de idade, indicando a necessidade de adaptação das aves à nova forma física. Produção de ovos, PMO, CA e GE não foram diferentes nas duas formas físicas, no período total. GP tendeu a ser maior durante todo o período para as aves com ração peletizada. A restrição de ração a $90 \%$ do consumo à vontade mostrou piores resultados para todas as variáveis estudadas e nenhuma forma física da ração foi capaz de compensar os efeitos negativos da restrição.

PALAVRAS-CHAVES: Peletização, postura, produção de ovos, restrição alimentar.

ABSTRACT

\section{EFFECT OF PHYSICAL FORM AND FEED RESTRICTION ON THE PERFORMANCE OF LIGHT LAYING HENS}

The experiment aimed at testing the effects of feed physical form (mash vs. pelleted) and feed allowance (ad libitum vs. 10\% restriction) in $160 \mathrm{H} \& \mathrm{~N}$ laying hens. Four treatments were applied, with 20 replications of two 26-44-week-old birds each in a completely randomized design, in a 2 x 2 factorial arrangement. Feed intake (FI), body weight gain (BWG), feed conversion (FC), egg production (EP), egg weight (EW) and egg specific gravity (EG) were evaluated. The mash diet provided greater FI in the total period $(\mathrm{P}<0.0001)$, whereas pelleted diet showed greater FI only after 42 weeks of age, indicating that birds need to adapt to the new physical form of diet. Egg production, EW, FC, and EG were not different for the two physical forms in the total period. BWG tended to be greater throughout the experiment period for birds eating pelleted diet. Ninety percent of feed restriction from ad libitum intake showed the worst results for all studied variables and none of the physical forms was able to compensate the negative effects of restriction.

KEYWORDS: Egg production, feed restriction, laying hens, pelleting. 


\section{INTRODUÇÃO}

A peletização de rações é amplamente difundida por suas vantagens, como a diminuição da carga microbiológica e a economia de energia gasta pelas aves ao se alimentarem dos peletes. Um dos resultados da peletização em frangos de corte é o aumento do consumo de ração, com consequente maior ganho de peso (CALET, 1965; MEINERZ et al., 2001; DALHKE et al., 2003). DALHKE et al. (2003), ao testarem três granulometrias para milho $(0,336 \mathrm{~mm}, 0,585 \mathrm{~mm}$ e $0,856 \mathrm{~mm}$ ), em dietas fareladas e peletizadas, concluíram que dietas peletizadas promoveram aumento no número de vilosidades no duodeno e que o incremento do tamanho das partículas promoveu criptas mais profundas e vilosidades duodenais mais altas, independentemente da forma física da dieta.

JENSEN et al. (1962) e NIR et al. (1994) relataram que o principal efeito da peletização é a redução da energia de mantença, aumentando a energia líquida de produção. SLINGER (1972) sugeriu que a peletização proporciona, em virtude das altas temperaturas do processo, a destruição térmica de fatores tóxicos que prejudicam a utilização dos nutrientes, aumentando a energia metabolizável da dieta. KLEIN et al. (1995), LECZNIESKI et al. (2001) e MAIORKA et al. (2005) verificaram que a peletização melhorou o consumo de ração e a eficiência de retenção da energia metabolizável aparente, quando comparada a dietas fareladas. Porém, notaram que frangos de corte consumindo rações peletizadas apresentam maior quantidade de gordura abdominal e total na carcaça e vísceras. LECZNIESKI et al. (2001) e MAIORKA et al. (2005) observaram que os benefícios da peletização foram mais evidentes em rações de baixa energia, já que o aumento dos níveis energéticos de uma dieta, além de proporcionar a melhoria na eficiência alimentar, diminui o consumo de ração, que é a variável com mais influência nos resultados positivos da peletização.

Segundo GARCIA (2003), a evolução genética de poedeiras tem resultado em aves com menor peso corporal, mais produtivas e de menor consumo, consequentemente mais exigentes nutricionalmente. $\mathrm{O}$ peso à maturidade fisiológica e a idade ao pico de produção também são menores, atualmente. PESTI (2005) observou que as melhorias genéticas oferecem atualmente linhagens de poedeiras bem adaptadas a diferentes ambientes, algumas com apetite menor do que outras, e com diferentes susceptibilidades à redução de consumo provocada pelo calor ambiental, sendo algumas dessas linhagens hábeis em manter eficiência alimentar e produção satisfatórias nessas condições. A literatura quanto ao uso de ração na forma peletizada para poedeiras é escassa. O aumento na densidade da ração via peletização pode ser a forma de estimular as poedeiras a um maior consumo e, portanto, a um melhor desempenho, o que justifica o estudo dessa prática. MEINERZ et al. (2001) concluíram que dietas peletizadas para frangos de corte são vantajosas em situação de dietas com baixa energia, semelhantemente às usadas com poedeiras. Esses autores notaram uma maior eficiência (kcal consumidas / kcal em ganho) em dietas de baixa energia, na forma peletizada.

No presente trabalho, estudou-se o efeito de duas formas físicas de rações (peletizadas e fareladas), com consumo à vontade ou restrito em $90 \%$ sobre o desempenho de poedeiras comerciais, no período de 26 a 44 semanas de idade. O modelo com restrição alimentar foi aplicado com o objetivo de uniformização, com base no conceito de que o consumo alimentar é uma variável que interfere diretamente nas respostas de desempenho (MEINERZ et al., 2001; DAHLKE, et al., 2003).

\section{MATERIAL E MÉTODOS}

Realizou-se o experimento no Laboratório de Ensino Zootécnico (LEZO) da Universidade Federal do Rio Grande do Sul. As aves foram alojadas em uma sala equipada com ar-condicionado para manejo de temperatura adequado conforme o manual da linhagem, em oitenta gaiolas metabólicas de $0,84 \mathrm{~m}^{2}$, dispostas em conjuntos de dois andares, com bebedouro tipo nipple e comedouro tipo calha. Em cada gaiola, alojaram-se duas aves, constituindo a unidade experimental (UE).

Foram alojadas 160 poedeiras leves da linhagem H\&N (nick chick), com vinte semanas de idade $\mathrm{e}$ peso médio de $1.350 \mathrm{~g}$, tendo sido manejadas na recria conforme o manual da linhagem (H \& N INTERNATIONAL, 1996). Usou-se período pré-experimental, de 20 a 25 semanas de idade das aves, para adaptação das aves ao ambiente, sendo alimentadas com uma única ração de produção, na forma farelada. Submeteram-se 
as aves a regime de luz artificial de $17 \mathrm{~h} / \mathrm{dia}$, com uma intensidade de 64 lúmens $/ \mathrm{m}^{2}$. O período experimental foi de 26 a 44 semanas de idade das aves, sendo dividido em quatro períodos de 28 dias e um quinto, de 21 dias. $O$ peso médio das aves com 26 semanas de idade foi de $1.550 \mathrm{~g} \mathrm{(} \pm 79 \mathrm{~g})$. Forneceu-se água à vontade e manteve-se controle de limpeza e das condições ambientais da sala.

Para a produção das rações pré-experimental e experimental, analisou-se proteína bruta do milho e do farelo de soja, bem como determinaram-se cálcio e fósforo no calcário calcítico e fosfato bicálcico. Dados de composição de nutrientes para os demais ingredientes foram obtidos das Tabelas do NRC (1994). A composição está apresentada na Tabela 1.

TABELA 1. Composição das dietas pré-experimental e experimentais

\begin{tabular}{|c|c|c|}
\hline & $\begin{array}{l}\text { Dieta pré- } \\
\text { experimental }\end{array}$ & $\begin{array}{l}\text { Dietas ex- } \\
\text { perimentais }\end{array}$ \\
\hline Ingredientes & $\begin{array}{l}20^{\mathrm{a}} \text { a } 25^{\mathrm{a}} \\
\text { semana }\end{array}$ & $\begin{array}{l}26^{\mathrm{a}} \text { a } 44^{\mathrm{a}} \\
\text { semana }\end{array}$ \\
\hline & $\%$ & $\%$ \\
\hline Milho & 60,94 & 56,81 \\
\hline Farelo de soja $44 \%$ & 26.62 & 27,95 \\
\hline Calcário calcítico & 8,43 & 9,82 \\
\hline Fosfato bicálcico & 1,45 & 1,69 \\
\hline Sal & 0,44 & 0,44 \\
\hline DL-metionina & 0,18 & 0,16 \\
\hline Óleo de soja & 1,79 & 2,98 \\
\hline Premix mineral* & 0,1 & 0,1 \\
\hline Premix vitamínico* & 0,05 & 0,05 \\
\hline Total & 100 & 100 \\
\hline & \multicolumn{2}{|c|}{$\begin{array}{c}\text { Composição nutricional } \\
\text { calculada }\end{array}$} \\
\hline EMA (kcal / EM/kg) & 2.800 & 2.800 \\
\hline Proteína bruta (\%) & 17,00 & 17,00 \\
\hline Cálcio (\%) & 3,60 & 4,0 \\
\hline Fósforo disponível (\%) & 0,40 & 0,45 \\
\hline Lisina dig $(\%)$ & 0,78 & 0,80 \\
\hline Metionina $\operatorname{dig}(\%)$ & 0,43 & 0,42 \\
\hline Metionina + cistína dig $(\%)$ & 0,75 & 0,73 \\
\hline Treonina dig (\%) & 0,57 & 0,58 \\
\hline
\end{tabular}

*Composição por quilo de ração: vit A 8.000 UI; vit D3 2.000 UI; vit E $10 \mathrm{UI}$; vit B1 2,5 mg; vit B2 4,0 mg; ; vit B6 $2 \mathrm{mg}$; vit B12 $10 \mathrm{mcg}$; vit; Vit K3 2,0 mg; ácido fólico 1,5 mg; ácido pantotênico 4,0 mg; ácido nicotínico $20 \mathrm{mg}$; biotina $0,35 \mathrm{mg}$; iodo $0,38 \mathrm{mg}$; ferro $25 \mathrm{mg}$; cobre 6,0 $\mathrm{mg}$; zinco $60,0 \mathrm{mg}$; manganês $85,0 \mathrm{mg}$; selênio $0,18 \mathrm{mg}$.
Compararam-se quatro tratamentos: ração farelada à vontade; ração farelada restrita a $90 \%$ do à vontade; ração peletizada à vontade e ração peletizada restrita a $90 \%$ do à vontade, sendo a restrição calculada com base no consumo voluntário médio do tratamento na semana anterior.

A dieta pré-experimental foi preparada com base em uma única partida de mistura. Prepararam-se as dietas experimentais com base em três misturas, suficientes para atender os períodos de 26 a 29 semanas, 30 a 41 semanas e 41 a 44 semanas, respectivamente. Para o processo de peletização, foi utilizada injeção máxima de vapor, com matriz de diâmetro dos furos de $5 / 32$ polegadas, tempo de oito segundos no condicionador e temperatura de $65-70^{\circ} \mathrm{C}$. O tamanho do pelete foi de $4 \mathrm{~mm}$. A partida do período de 26 a 29 semanas resultou em alta quantidade de finos (70\%). Para as partidas subsequentes, moeram-se o milho e o farelo de soja com peneira de $4 \mathrm{~mm}$, visando diminuir o percentual de finos, que efetivamente baixou para $25 \%$ a $30 \%$. A granulometria das partículas, determinada antes da peletização, mostrou valores de $0,878 \mathrm{~mm}$ para a primeira mistura, valor inadequado a uma boa qualidade de pelete, e justificou uma melhor moagem para as demais misturas, obtendo-se, 0,478 e $0,471 \mathrm{~mm}$.

Ao término de cada semana, determinou-se o consumo de ração (CR). A restrição foi definida como $90 \%$ do consumo à vontade de cada tratamento na semana anterior, sendo este valor aplicado na semana seguinte aos tratamentos restritos, à semelhança do trabalho de MEINERZ et al. (2001).

Procedeu-se à avaliação da produção de ovos, com base na coleta diária entre as 17:00 e 18:00 horas, a conversão alimentar (CA), expressa em (kg de ração/ $\mathrm{kg}$ de ovos), o peso médio dos ovos (PMO) em gramas e a gravidade específica (GE). Os pesos corporais (PC) e ganhos de peso (GP) foram obtidos a cada período experimental.

O experimento foi instalado no modelo fatorial $2 \times 2$ (forma física x restrição alimentar), num delineamento completamente casualizado. Submeteram-se os dados coletados à análise de variância e ao teste $\mathrm{F}$, para comparação de médias. As interações significativas foram analisadas por contraste de um grau de liberdade utilizando o t-teste. Empregou-se o programa de análise estatística Statistix for Windows (1996). 


\section{RESULTADOS E DISCUSSÃO}

$\mathrm{O}$ CR foi influenciado significativamente $(\mathrm{P}<0,05)$ pela forma física da ração nos períodos 1,2 e 3 e no período total de produção (Tabela 2), com maior consumo para as dietas fareladas, provavelmente em função de as poedeiras não estarem adaptadas às dietas peletizadas. A partir do período 4 , observou-se uma equalização de consumo entre as duas formas físicas, indicando uma provável adaptação das aves à peletização. No período 5 , pela primeira vez, houve um maior $\mathrm{CR}$, embora não significativo para as rações peletizadas, reforçando a hipótese comportamental de que as aves adaptam-se a consumir ração peletizada.

Não houve interação entre os fatores estudados no período total. No entanto, no período 2 e no período 5 houve interação entre os fatores $(\mathrm{P}<0,019$ e $\mathrm{P}<0,029$, respectivamente). $\mathrm{O}$ segundo período experimental foi marcado por uma queda significativa no consumo de ração das aves com a dieta peletizada $(\mathrm{P}<0,001)$, coincidindo com a oferta de peletes mais íntegros, ao contrário do primeiro período. No quinto período, houve a inversão de preferência e as aves passaram a comer mais a dieta peletizada à vontade $(\mathrm{P}<0,015)$. Já com as dietas restritas, não houve diferença significativa entre os consumos das dietas peletizada e farelada. Nos trabalhos com peletização em frangos de corte (LECZNIESKI et al., 2001; MEINERZ et al., 2001), observa-se que aves submetidas a dietas peletizadas comem mais, comportamento esse que está relacionado à facilidade de apreensão do alimento. NIR et al. (1994) afirmam que as aves têm dificuldade em comer alimentos muito maiores ou muito menores do que o tamanho de seu bico e este fato fica claro em dietas fareladas que apresentam granulometria muito pequena (abaixo de 0,5 $\mathrm{mm}$ ) (RIBEIRO et al., 2002; DALHKE et al., 2003). Em poedeiras, a debicagem é um fator extra que poderia exercer influência na apreensão do alimento. ODA et al. (2000) e PERSYN et al. (2004) não encontraram diferenças no consumo entre aves debicadas e não debicadas, mas observaram que as debicadas gastaram mais tempo para se alimentar do que as não debicadas, apresentando seletividade ao comer, o que pode ter sido um fator determinante na demora das poedeiras em se adaptar à dieta peletizada. Dessa maneira, no presente experimento, não ficou claro o benefício da peletização no que diz respeito ao aumento de consumo de ração

TABELA 2. Consumo de ração ( $\mathrm{g}$ ) nos períodos $1,2,3,4$, e 5 e no período total (g/ave/dia)

\begin{tabular}{|c|c|c|c|c|c|c|c|}
\hline & & $\begin{array}{c}\text { Período } 1 \\
(26-29)\end{array}$ & $\begin{array}{c}\text { Período } 2 \\
(30-33)\end{array}$ & $\begin{array}{c}\text { Período } 3 \\
(34-37)\end{array}$ & $\begin{array}{c}\text { Período } 4 \\
(38-41)\end{array}$ & $\begin{array}{c}\text { Período } 5 \\
(42-44)\end{array}$ & $\begin{array}{c}\text { Total } \\
(26-44)\end{array}$ \\
\hline \multicolumn{8}{|c|}{ Forma física } \\
\hline \multicolumn{2}{|l|}{ Farelada } & $104 a$ & $104 a$ & $105 a$ & 105 & 105 & $105 \mathrm{a}$ \\
\hline \multicolumn{2}{|l|}{ Peletizada } & $102 b$ & $101 b$ & $103 b$ & 105 & 106 & $103 b$ \\
\hline \multicolumn{8}{|c|}{ Restrição alimentar } \\
\hline \multicolumn{2}{|c|}{ À vontade } & $107 \mathrm{a}$ & $108 \mathrm{a}$ & $110 \mathrm{a}$ & $111 \mathrm{a}$ & $113 a$ & $110 \mathrm{a}$ \\
\hline \multicolumn{2}{|l|}{ Restrita } & $99 b$ & $98 b$ & $98 b$ & $98 b$ & $99 b$ & $98 b$ \\
\hline \multicolumn{8}{|l|}{ Interação } \\
\hline \multirow[t]{2}{*}{ Farelada } & À vontade & 108 & 110 & 111 & 111 & 111 & 111 \\
\hline & Restrita & 100 & 99 & 99 & 99 & 99 & 99 \\
\hline \multirow[t]{2}{*}{ Peletizada } & À vontade & 106 & 105 & 108 & 111 & 114 & 109 \\
\hline & Restrita & 98 & 98 & 98 & 98 & 99 & 98 \\
\hline \multicolumn{8}{|c|}{ Probabilidades } \\
\hline \multicolumn{2}{|c|}{ Forma física } & 0,03 & 0,001 & 0,01 & ns & $\mathrm{ns}$ & 0,02 \\
\hline \multicolumn{2}{|c|}{ Restrição alimentar } & 0,001 & 0,001 & 0,001 & 0,001 & 0,001 & 0,001 \\
\hline \multicolumn{2}{|c|}{ Forma $x$ oferta } & $\mathrm{ns}$ & 0,019 & $\mathrm{~ns}$ & $\mathrm{~ns}$ & 0,029 & ns \\
\hline \multirow{2}{*}{\multicolumn{2}{|c|}{ CV $(\%)$}} & 3,9 & 4,4 & 3,1 & 3,3 & 2,9 & 2,7 \\
\hline & & & Contrastes & & & & \\
\hline \multicolumn{2}{|l|}{ FAV x PAV } & & 0,001 & & & 0,015 & \\
\hline \multicolumn{2}{|l|}{ FR $x$ PR } & & $\mathrm{ns}$ & & & ns & \\
\hline
\end{tabular}

${ }^{\text {abc }}$ Médias com letras diversas na coluna diferem entre si pelo teste de Tukey $(\mathrm{P}<0,05)$.

$\mathrm{FA}=$ farelada à vontade; $\mathrm{PAV}=$ peletizada à vontade; $\mathrm{FR}=$ farelada restrita; $\mathrm{PR}=$ peletizada restrita. 
Não houve interação significativa entre a forma física e a restrição alimentar sobre o GP acumulado (Tabela 3). No entanto, a ração peletizada influenciou positivamente o GP acumulado em quase todos os períodos, resposta esta que está de acordo com os dados de VILARIÑO et al. (1996), que encontraram um maior GP com ração peletizada. É interessante notar que, apesar de o CR ter sido maior para as rações fareladas (à exceção do período 5), as poedeiras responderam positivamente às dietas peletizadas em GP, indicando que essa forma física proporcionou maior disponibilidade de energia. Esse dado está de acordo com o relatado por JENSEN et al. (1962) e NIR et al. (1994), que afirmam que o principal efeito da peletiza- ção é a redução na energia de mantença, aumentando a energia líquida de produção. A forma peletizada pode, porém, levar a um indesejável aumento de peso corporal das poedeiras. No entanto, reduções de peso corporal estão associadas à redução no peso de ovo e, em geral, ao declínio na massa de ovos produzida. HARMS et al. (1981) observaram que o incremento de $100 \mathrm{~g}$ no peso corporal de poedeiras com 28 semanas de idade resultou em $4,5 \%$ de incremento no consumo de ração associado a um aumento no peso e na massa de ovos. No presente experimento, observou-se que a limitação no ganho de peso das aves sob restrição alimentar, principalmente nos períodos 4 e 5 , coincidiu com a queda nas respostas de produção (Tabela 4).

TABELA 3. Ganho de peso (g) acumulado das poedeiras nos períodos de produção

\begin{tabular}{|c|c|c|c|c|c|c|}
\hline Forma física & $\begin{array}{l}\text { Restrição } \\
\text { alimentar }\end{array}$ & $\begin{array}{c}\text { Período } 1 \\
(26-29 \text { sem.) }\end{array}$ & $\begin{array}{c}\text { Período } 2 \\
\text { (26-33 sem.) }\end{array}$ & $\begin{array}{c}\text { Período } 3 \\
(26-37 \text { sem.) }\end{array}$ & $\begin{array}{c}\text { Período } 4 \\
\text { (26-41 sem.) }\end{array}$ & $\begin{array}{c}\text { Total } \\
\text { (26-44 sem.) }\end{array}$ \\
\hline \multicolumn{7}{|c|}{ Forma física } \\
\hline Farelada & & 43 & $86 \mathrm{~b}$ & 81 & 50 & $39 b$ \\
\hline Peletizada & & 60 & $121 \mathrm{a}$ & 108 & 72 & $80 \mathrm{a}$ \\
\hline \multicolumn{7}{|c|}{ Restrição alimentar } \\
\hline À vontade & & $67 \mathrm{a}$ & $135 \mathrm{a}$ & $140 \mathrm{a}$ & $101 \mathrm{a}$ & $133 \mathrm{a}$ \\
\hline Restrita & & $33 b$ & $72 b$ & $49 b$ & $22 b$ & $-11 b$ \\
\hline \multicolumn{7}{|l|}{ Probabilidades } \\
\hline Forma física & & ns & 0,003 & $\mathrm{~ns}$ & ns & 0,020 \\
\hline Restrição alime & & 0,001 & 0,001 & 0,001 & 0,001 & 0,001 \\
\hline Forma $x$ oferta & & ns & ns & ns & ns & ns \\
\hline C.V. (\%) & & 5,5 & 12,4 & 15,8 & 23,4 & 16,8 \\
\hline
\end{tabular}

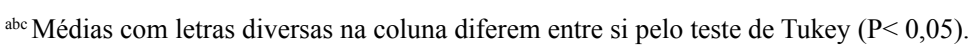

A restrição alimentar resultou em menor ganho de peso das aves $(\mathrm{P}<0,001)$. Mesmo assim, aves com rações peletizadas restritas ganharam mais peso do que suas companheiras que recebiam rações fareladas restritas, como pode ser observado na Tabela 3. No período 5, as aves restritas entraram em balanço negativo, perdendo peso, o que se deve principalmente ao consumo de ração farelada.

$\mathrm{Na}$ Tabela 4 estão apresentadas as produções de ovos. Não houve interação significativa entre a forma física e a restrição alimentar sobre esta resposta nos diferentes períodos testados. No que diz respeito à forma física, a PO das aves recebendo ração farelada foi superior apenas no período $2(\mathrm{P}<0,010)$, resultado coerente com as respostas em consumo alimentar e antagônico ao ganho de peso. Nos demais períodos e no total, as formas físicas não afetaram a PO. Esses resultados indicam que o ganho de peso foi uma resposta mais fácil de ser afetada do que a produção de ovos, e que provavelmente as aves direcionaram nutrientes de reservas corporais para a manutenção da PO. Nota-se, porém, que no período 5 a PO das aves com ração farelada à vontade teve uma queda de cinco pontos percentuais, comparada à das aves com ração 
peletizada à vontade (90\% vs 95\%). Quanto à restrição alimentar, a PO foi superior em quase todos os períodos de produção nas aves alimentadas à vontade comparadas àquelas com restrição alimentar, com uma queda, para estas últimas, no período total, de 7\%. A restrição foi bastante severa, tendo mantido a produção acima de $80 \%$ por apenas dezesseis semanas, ficando abaixo, portanto, do potencial da linhagem. BELL (1998) citou uma queda de $4 \%$ na produção nas aves que receberam restrição de 7\% de alimento. MATSOUKAS et al. (1980) registraram uma queda de $5 \%$ na produção de ovos com uma restrição de $10 \%$ no consumo de ração. Nenhuma das formas físicas testadas foi capaz de compensar o efeito da restrição alimentar.

O efeito das dietas sobre a conversão alimentar ( $\mathrm{kg} / \mathrm{kg}$ de ovos) está na Tabela 5. Não houve interação significativa entre a forma física e restrição alimentar. A CA somente foi influenciada estatisticamente pela forma física no período 3 , quando foi melhor para as aves recebendo ração peletizada $(\mathrm{P}<0,001)$. Conversão alimentar é uma medida importante, já que os benefícios da peletização se baseiam na melhoria da eficiência alimentar, transformando a energia disponível em maior produção. $\mathrm{O}$ tempo necessário para as aves adaptarem-se à dieta peletizada, especialmente nos períodos 1 e 2, com diminuição no $\mathrm{CR}$, pode ser a causa da inobservância dessa vantagem. $O$ fato de as aves com ração peletizada terem ganho mais peso, e a ausência de efeito na CA, sugere que os ganhos da peletização não foram direcionados à produção de ovos e sim a ganhos de tecido corporal.

TABELA 4. Produção de ovos (\%) nos cinco períodos experimentais e no período total

\begin{tabular}{|c|c|c|c|c|c|c|c|}
\hline Forma física & $\begin{array}{l}\text { Restrição } \\
\text { alimentar }\end{array}$ & $\begin{array}{c}\text { Período } 1 \\
\text { (26-29 sem.) }\end{array}$ & $\begin{array}{c}\text { Período } 2 \\
\text { (30-33 sem.) }\end{array}$ & $\begin{array}{c}\text { Período } 3 \\
\text { (34-37 sem.) }\end{array}$ & $\begin{array}{c}\text { Período } 4 \\
(38-41 \text { sem.) }\end{array}$ & $\begin{array}{c}\text { Período } 5 \\
\text { (42-44 sem.) }\end{array}$ & $\begin{array}{c}\text { Total } \\
(26-44 \text { sem. })\end{array}$ \\
\hline \multicolumn{8}{|c|}{ Forma física } \\
\hline Farelada & & 94 & $94 \mathrm{a}$ & 91 & 89 & 85 & 91 \\
\hline Peletizada & & 94 & $90 \mathrm{~b}$ & 93 & 88 & 85 & 90 \\
\hline \multicolumn{8}{|c|}{ Restrição alimentar } \\
\hline À vontade & & $95 \mathrm{a}$ & 83 & $95 \mathrm{a}$ & $95 \mathrm{a}$ & $92^{\mathrm{a}}$ & $94 a$ \\
\hline Restrita & & $93 b$ & 92 & $89 b$ & $83 b$ & $77 b$ & $87 b$ \\
\hline \multicolumn{8}{|c|}{ Probabilidades } \\
\hline \multicolumn{2}{|c|}{ Forma física } & ns & 0,010 & ns & ns & ns & ns \\
\hline \multicolumn{2}{|c|}{ Restrição alimentar } & 0,033 & ns & 0,001 & 0,001 & 0,001 & 0,001 \\
\hline \multirow{2}{*}{\multicolumn{2}{|c|}{ Forma $x$ oferta }} & ns & ns & ns & ns & ns & ns \\
\hline & C.V. $(\%)$ & 3,8 & 7,2 & 5,9 & 10,5 & 14,3 & 5,7 \\
\hline
\end{tabular}

${ }^{\text {abc }}$ Médias com letras diversas na coluna diferem entre si pelo teste de Tukey $(\mathrm{P}<0,05)$.

TABELA 5. Conversão alimentar $(\mathrm{kg} / \mathrm{kg})$, em $\mathrm{kg}$ de ração/ $\mathrm{kg}$ de ovos, nos períodos 1,2 , 3, 4, e 5 e no período total

\begin{tabular}{|c|c|c|c|c|c|c|c|}
\hline Forma física & $\begin{array}{l}\text { Restrição } \\
\text { alimentar }\end{array}$ & $\begin{array}{c}\text { Período } 1 \\
\text { (26-29 sem.) }\end{array}$ & $\begin{array}{c}\text { Período } 2 \\
\text { (30-33 sem.) }\end{array}$ & $\begin{array}{c}\text { Período } 3 \\
\text { (34-37 sem.) }\end{array}$ & $\begin{array}{c}\text { Período } 4 \\
(38-41 \text { sem.) }\end{array}$ & $\begin{array}{c}\text { Período } 5 \\
\text { (42-44 sem.) }\end{array}$ & $\begin{array}{c}\text { Total } \\
(26-44 \text { sem.) }\end{array}$ \\
\hline \multicolumn{8}{|c|}{ Forma Física } \\
\hline Farelada & & 1,87 & 1,83 & $1,86 \mathrm{~b}$ & 1,88 & 1,98 & 1,86 \\
\hline Peletizada & & 1,86 & 1,85 & $1,77 \mathrm{a}$ & 1,86 & 1,98 & 1,83 \\
\hline \multicolumn{8}{|c|}{ Restrição alimentar } \\
\hline À vontade & & $1,91 b$ & $1,89 b$ & 1,82 & $1,82^{\mathrm{a}}$ & $1,89 \mathrm{a}$ & 1,86 \\
\hline Restrita & & $1,83 \mathrm{a}$ & $1,78 \mathrm{a}$ & 1,81 & $1,93 b$ & $2,08 \mathrm{~b}$ & 1,84 \\
\hline \multicolumn{8}{|c|}{ Probabilidades } \\
\hline Forma física & & ns & ns & 0,001 & Ns & ns & ns \\
\hline Restrição alin & & 0,001 & 0,001 & ns & 0,024 & 0,025 & ns \\
\hline Forma $x$ ofert & & ns & ns & ns & Ns & ns & ns \\
\hline C.V. $(\%)$ & & 5,6 & 7,1 & 6,4 & 11,5 & 18,9 & 5,3 \\
\hline
\end{tabular}

${ }_{\text {abc }}$ Médias com letras diversas na coluna diferem entre si pelo teste de Tukey $(\mathrm{P}<0,05)$ 
Quanto à restrição alimentar, a CA foi melhor nas aves que receberam ração restrita nos períodos $1 \mathrm{e}$ 2. Porém nos períodos 4 e 5 houve uma inversão: aves com ração à vontade passaram a ter melhor CA. Para o período total, em função dessas variações, não houve diferença estatística entre restrição e à vontade. No entanto, a melhor CA das aves que sofreram restrição alimentar não deve ser interpretada diretamente como benefício; na prática, esse parâmetro avalia a conversão de ração em ovos sem considerar as variações de peso corporal das aves. Consequentemente, parte da eficiência observada é atribuída ao crescimento reduzido das aves e/ou ao desvio das reservas corporais para a produção de ovos. Já a piora na CA nos períodos 4 e 5 pode indicar um esgotamento das reservas nutricionais das aves.
Na Tabela 6 encontram-se os pesos médios de ovos (PMO). Não houve interação significativa entre os fatores. Para forma física, somente no período 4, o $\mathrm{PMO}$ das aves com ração peletizada foi superior ( $\mathrm{P}<$ 0,05). A restrição diminuiu o PMO em quase todos os períodos. Neste experimento, foram encontrados valores de até $4 \%$ a menos no peso dos ovos produzidos por aves alimentadas com restrição, maiores do que os encontrados por MATSOUKAS et al. (1980), que observaram uma redução de $2,4 \%$ no peso, e de MARTIN (1998), que encontraram 1,3 \% de redução de peso dos ovos com os mesmos $10 \%$ de restrição alimentar. A restrição alimentar foi prejudicial em quase todos os períodos.

TABELA 6. Peso médio dos ovos (g) nos períodos $1,2,3$, 4, e 5 e no período total

\begin{tabular}{|c|c|c|c|c|c|c|c|}
\hline Forma física & $\begin{array}{l}\text { Restrição } \\
\text { alimentar }\end{array}$ & $\begin{array}{c}\text { Período } 1 \\
(26-29 \text { sem.) }\end{array}$ & $\begin{array}{c}\text { Período } 2 \\
(30-33 \text { sem.) }\end{array}$ & $\begin{array}{c}\text { Período } 3 \\
\text { (34-37 sem.) }\end{array}$ & $\begin{array}{c}\text { Período } 4 \\
\text { (38-41 sem.) }\end{array}$ & $\begin{array}{c}\text { Período } 5 \\
\text { (42-44 sem.) }\end{array}$ & $\begin{array}{c}\text { Total } \\
(26-44 \text { sem.) }\end{array}$ \\
\hline \multicolumn{8}{|c|}{ Forma física } \\
\hline Farelada & & 59 & 61 & 62 & $63 b$ & 65 & 62 \\
\hline Peletizada & & 59 & 61 & 62 & $65 \mathrm{a}$ & 65 & 63 \\
\hline \multicolumn{8}{|c|}{ Restrição alimentar } \\
\hline À vontade & & 59 & $62 \mathrm{a}$ & $64 a$ & $65 \mathrm{a}$ & 65 & $63 \mathrm{a}$ \\
\hline Restrita & & 58 & $60 \mathrm{~b}$ & $61 b$ & $63 b$ & 65 & $62 b$ \\
\hline \multicolumn{8}{|c|}{ Probabilidades } \\
\hline Forma física & & $\mathrm{ns}$ & ns & ns & 0,05 & ns & ns \\
\hline Restrição alime & & ns & 0,001 & 0,001 & 0,01 & $\mathrm{~ns}$ & 0,01 \\
\hline Forma $x$ oferta & & $\mathrm{ns}$ & $\mathrm{ns}$ & ns & ns & $\mathrm{ns}$ & $\mathrm{ns}$ \\
\hline C.V. $(\%)$ & & 4,7 & 4,0 & 4,4 & 5,5 & 5,7 & 4,1 \\
\hline
\end{tabular}

${ }^{a b c}$ Médias com letras diversas na coluna diferem entre si pelo teste de Tukey $(\mathrm{P}<0,05)$

Com relação à gravidade específica (dados não apresentados), não ocorreu interação significativa entre a forma física e a restrição alimentar em nenhum dos períodos de produção. Também não houve efeito da forma física da ração sobre essa resposta, já que a restrição alimentar somente influenciou negativamente a GE no período $4(\mathrm{P}<0,04)$.

Analisando os resultados à luz do consumo de nutrientes, as dietas fornecidas à vontade, fareladas ou peletizadas, atenderam às exigências determinadas pelo manual da linhagem e pelo NRC (1994). Apenas no período 2 houve queda de $5,5 \%$ do consumo de energia metabolizável (EM) nas aves alimentadas com ração peletizada à vontade em relação às exigências, e isto se refletiu na queda de produção de ovos. Foi observado que os consumos médios de EM variando de 293 a $318 \mathrm{kcal} /$ dia nas aves alimentadas à vontade tiveram um efeito significativo sobre o peso final com 44 semanas e sobre o ganho de peso. No entanto, as aves com restrição alimentar consumiram somente 277 $\mathrm{kcal} / \mathrm{dia}$, podendo esta ser considerada a maior limitação ao desempenho produtivo desses tratamentos. Os resultados de SAKOMURA et al. (1993) com matrizes pesadas e poedeiras de linhagens da Universidade Federal de Viçosa mostraram que o consumo restrito de energia, variando de 259 a $268 \mathrm{kcal} /$ dia, entre 37 e 52 semanas, causou uma queda de $3,4 \%$ na produção de ovos em relação ao consumo à vontade.

A restrição alimentar de $10 \%$ ao longo dos diferentes períodos de produção de uma maneira geral 
significou uma redução de $12 \%$ nas exigências de EM descritas para a linhagem (H \& N INTERNATIONAL, 1996). Essa redução foi similar para ambas as formas físicas. Os efeitos dessa limitação foram cumulativos, visto que, no período 5, a restrição alimentar provocou uma queda de $16,5 \%$ na produção de ovos, semelhante ao observado por CERNIGLIA et al. (1984).

No presente experimento, as aves alimentadas à vontade ingeriram $789 \mathrm{mg} /$ ave/dia de aminoácidos sulfurados (AAS). Já as aves que sofreram restrição alimentar tiveram um consumo de $710 \mathrm{mg} / \mathrm{ave} / \mathrm{dia}$ desses aminoácidos. É aceito que a primeira resposta a ser afetada com uma redução de AAS é o peso de ovos. JENSEN \& PENZ Jr. (1990) evidenciaram que um consumo de $633 \mathrm{mg}$ de AAS promoveu um peso médio de ovos de 57g. WALDROUP \& HELLWIG (1995), avaliando lotes de poedeiras em quatro períodos de produção, observaram que os consumos variaram entre 601 e $690 \mathrm{mg} /$ dia de AAS para obtenção de máxima produção diária, massa e peso de ovos. Portanto, as aves do presente experimento, mesmo com restrição alimentar, não tiveram restrição em AAS que justificasse alguma queda de PO.

\section{CONCLUSÕES}

A forma física da ração para poedeiras não afeta a produção, o peso e a gravidade específica dos ovos. Não se recomenda a peletização de rações para poedeiras de linhagens atuais. Nenhuma das formas físicas foi capaz de compensar a restrição de consumo imposta às aves.

\section{REFERÊNCIAS}

ASSOCIATION OF OFFICIAL ANALYTICAL CHEMISTS. Official methods of analysis. 12. ed. Washington: Willian Horwitz, 1984. $1094 \mathrm{p}$.

AUKLAND, J. N.; FULTON, R. B. Effects of restricting the energy intake of laying hens. British Poultry Science, v. 14, n. 6, p. 579-588, 1973.

BELL, D. Economic aspects in Layer. In: SEMINAR IN AVIAN PATHOLOGY AND PRODUCTION, 1998, Athens. Proceedings... Athens: AMEVEA, 1998. p. 201-221.

BIAGI, J. D. Tecnologia da peletização de rações, In: SIMPÓSIO DO COLÉGIO BRASILEIRO DE NUTRIÇÃO ANIMAL, 3., 1990, Campinas. Anais... Campinas: CBNA, 1990. p. 37-59.
CALET, C. The relative value of pellets versus mash and grain in poultry nutrition. World's Poultry Science Journal, v. 21, n. 1 p. 32-52, 1965.

CERnigliA, G. J.; GOOdling, A. C.; Hebert, J. A. Production performance of White Leghorn layers on limited feed. Poultry Science, v. 63, n. 6, p. 1105-1109, 1984.

CUNNINGHAM, D. L. A comparison of controlled feeding programs for maximizing returns of White Leghorn layers, Poultry Science, v. 63, n. 10, p. 2352-2357, 1984.

DALHKE, F. ; RIBEIRO, A. M. L.; KESSLER, A. M. LIMA, A. R.; MAIORKA, A. Effect of corn particle size and physical form of the diet on the gastrointestinal structures of broiler chickens. Brazilian Journal of Poultry Science, v. 5, n. 1, p. 61-67, 2003.

DE GROOTE, G. The application of three methods of moderate energy restriction for light hybrid laying hens. In: WORLD'S POULTRY CONGRESS, 16., 1978, London. Proceedings... London: World Poultry Science, 1978. p. 84-88.

DUNCAN, I. J. H.; SLEE, G. S.; SEAWRIGHT, E. Behavioral consequence of partial beak amputation (beak trimming) in poultry. British Poultry Science, v. 30, n. 3, p. 479-488, 1989.

GARCIA, J. R. Avanços na nutrição da poedeira moderna. In: SIMPÓSIO DE NUTRIÇÃO E MANEJO DE AVES E SUÍNOS, 2003, Campinas. Anais... Campinas: CBNA, 2003. p. 35.

HAMILTON, R. M. G. Methods and factors that affect the measurement of egg shell quality. Poultry Science, v. 61, p. 20022039, 1982.

HARMS, R. H. Specifications for feeding commercial layers based on daily feed intake. Feedstuffs, v. 53, n. 47, p. 40-41, 1981.

H \& N INTERNATIONAL. H \& N Nick Chick layer Management Program. Redmond, WA: H \& N INTERNATIONAL. 1996. p. 32.

HY LINE VARIETY. Guia de manejo, 2003-2005. p. 15. Disponível em: <http://www.hylinedobrasil.com.br/website/production/ downloads/guia_w36E_final.pdf> Acesso em: 23 fev. 2007.

JENSEN, L. S.; MERRIL, L. H.; REDDY, C. V. Observations on eating patterns and rate of food passage of birds fed pelleted and unpelleted diets. Poultry Science, v. 41, p. 1414-1419, 1962.

JENSEN, L. S.; PENZ Jr., A. M. Egg weight and components as influenced by dietary protein and amino acids. In: GEORGIA NUTRITION CONFERENCE FOR FEED INDUSTRY, 1990, Atlanta. Proceedings...Atlanta, Georgia, 1990. p. 107-112.

KLEIN, C. H.; KESSLER, A. M.; PENZ Jr., A. M. Efeito da forma física da ração sobre alguns parâmetros do metabolismo 
energético de frangos de corte. In: REUNIÃO DA SOCIEDADE BRASILEIRA DE ZOOTECNIA, 1995, Brasília. Anais... Brasília, DF, 1995. p. 482-483.

LECZNIESKI, J. L. ; RIBEIRO, A. M. L. ; KESSLER, A. M.; PENZ Jr. A. M. Influência da forma física e do nível de energia da ração no desempenho e na composição de frangos de corte. Archivos Latinoamericanos de Producción Animal, v. 9, n. 1, p. 6-11, 2001.

LEE, H. Y.; CRAIG, J. V. Beak trimming effects on the behavior and the weight gain of floor reared egg-strain pullets from three genetic stocks during the rearing period. Poultry Science, v. 69 , n. 4 , p. $568-575,1990$.

MAIA, G. A. R.; FONSECA, J. B.; SOARES, R. T. R. N. et al. Qualidade dos ovos de poedeiras comerciais alimentadas com levedura seca de cana-de-açúcar. Pesquisa Agropecuária Brasileira, v. 37, n. 9, p. 1295-1300, 2002.

MAIORKA, A.; DAHLKE, F. ; PENZ Jr., A. M. ; KESSLER, A. M. Diets formulated on total or digestible amino acid basis with different energy levels and physical form on broiler performance. Revista Brasileira de Ciência Avícola, v. 7, n. 1, p. 47-50, 2005.

MARTIN, M. Fontes de desperdício na produção de ovos comerciais. In: SIMPÓSIO GOIANO DE AVICULTURA, 3., 1998, Goiânia. Anais... Goiânia: SGA, 1998.

MATSOUKAS, J.; SKOLUND, W. C.; WHITTAKER, D. Feed restriction in Laying hens. Poultry Science, v. 59, p. 693-696, 1980.

MEINERZ, C.; RIBEIRO,A. M. L.; PENZ Jr., A. M. ; KESSLER, A. M. K. Níveis de energia e peletização no desempenho e rendimento de carcaças de frangos de corte com oferta alimentar equalizada. Revista Brasileira de Zootecnia, v. 30, n. 6, p. 20262032, 2001.

MORAN, Jr. E. T. Effects of pelleting quality on the performance of meat birds. In: RECENT ADVANCES IN ANIMAL NUTRITION, 1989, London. Proceedings... London: Haresing, 1989. p. $87-108$.

NATIONAL RESEARCH COUNCIL. Nutrient requirements of domestic animals: nutrient requirements of poultry. 9. ed. Washington: National academy Press, 1994, 115 p.

NEME, R.; SAKOMURA, N. K.; FUKAYAMA, E. H. Curvas de crescimento e deposição dos componentes corporais em aves de postura de diferentes linhagens. Revista Brasileira de Zootecnia, v. 35, n. 3, p. 1091-1100. 2006 (supl).

NIR, I; HILLEI, R.; SHEFET, G. Effect of particle size on performance: 1. Corn. Poultry Science, v. 73, p. 45-49, 1994.

ODA, P. K.; MORES, de V. M. B.; ARIKI, J. ARIKI, J.; MALHEIROS, R. D.; FURLAN, R. L.; KRONKA, S. N. Desempenho comparativo entre duas linhagens de poedeiras comerciais debicadas em diferentes idades na fase de recria. Ciência Rural, v. 30, n. 4, p. 693-698, 2000.

PERSYN, K. E.; XIN, H.; NETTLETON, D.; IKEGUCHI, A; GATES, R. S. Feeding behaviors of laying hens with or without beak trimming. Transactions of the ASAE, v. 47, n. 2, p. 591596, 2004.

PESTI, G. M. Practical commercial egg layer feeds. In: Poultry nutrition and feeding: a text book. Trafford: Victoria BC, 2005. Cap. 30.

RIBEIRO, A. M. L.; MAGRO, N.; PENZ JR, A. M. Granulometria do milho em rações de crescimento de frangos de corte e seu efeito no desempenho e metabolismo. Revista Brasileira de Ciência Avícola / Brazilian Journal of Poultry Science, v. 4, n. 1, p. 47-54, 2002.

SAKOMURA, N. K.; ROSTAGNO, H. S. ; SOARES, P. R. SANCHEZ, G. Determinação das equações de predição da exigência nutricional de energia para matrizes pesadas e poedeiras. Revista Brasileira de Zootecnia, v. 22, n. 5, p. 723-731, 1993.

SIBBALD, I. R. The effect of steam pelleting on the true metabolizable energy values of poultry diets. Poultry Science, v. 56, p. 1686-1688, 1977.

SLINGER, S. J. Effect of pelleting and crumbling methods on the nutritional values of feeds. In: EFFECT OF PROCESSING ON THE NUTRITIONAL VALUE OF FEEDS, 1972, Gainesville. Proceedings... Gainesville: Limerick, 1972. p. 48-66.

VILARIÑO, M.; PICARD, M. L.; MELCION, J. P.; FAURE, J. M. Behavioural adaptation of laying hens to diluition of diets under mash and pellet form. British Poultry Science, v. 37, p. 895-907, 1996.

WALDROUP, P. W.; HELWIG, H. M. Methionine and total sulfur amino acid requirements influenced by stage of production. Journal of Applied poultry Research, v. 4, p. 283-292, 1995. 